\title{
Glasgow Coma Scale, Brain Computerized Tomography and Neurophysiological Methods as Prognostic Factors of Pediatric Coma
}

\section{Mohammad W. El-Anwar ${ }^{1}$, Waleed M. Ibrahim² ${ }^{2}$ Sanaa M. Abdel Salam ${ }^{3 *}$, Safaa H.A. Saleh ${ }^{3}$, Mohammad A. Zeidan ${ }^{4}$ and Moanes A. Enaba ${ }^{5}$}

${ }^{1}$ Otorhinolaryngology, Department Faculty of Medicine, Zagazig University, Egypt

${ }^{2}$ Audiology, Department Faculty of Medicine, Zagazig University, Egypt

${ }^{3}$ Pedatrics, Department Faculty of Medicine, Zagazig University, Egypt

${ }^{4}$ Anesthesia and Intensive Care, Department Faculty of Medicine, Zagazig University, Egypt

${ }^{5}$ Radiology, Department Faculty of Medicine, Zagazig University, Egypt

\begin{abstract}
Background and objectives: Coma is characterized by the total absence of both arousal and awareness. The outcome of coma depends on the etiology, depth and duration of impaired consciousness.

It is likely that brain electrical function monitoring will play an increasingly important role in evaluating prognosis of coma in children.

Aim: To compare the predictive values of clinical examinations combined with the recordings of Electroencephalography (EEG) and Brainstem Auditory-Evoked Potentials (BAEP) and computed tomography (CT) of the brain in the evaluation of coma outcome in children.

Methods: Twenty children with coma aged 3-14 years were included in the study and subjected to: full history, clinical, neurological and otological examination. Medical investigations for coma, EEG, CT brain and auditory brainstem evoked potential (BAEP) measurements were performed for all patients. They were subdivided into 2 groups: group 1 included 8 patients with surgical causes of coma, group 2 include 12 patients with medical causes of coma.

Results: There was younger age, lower Glasgow Coma Scale (GCS) and more significant incidence of unfavourable outcome (death, disability) in patients of surgical coma (group 1). A significant difference between both groups was observed regarding the presence of brain edema and intracranial hemorrhage (100\% in group 1) while normally visualized basal cisterns were significantly more in group (2) $(p=0.02)$. Favourable outcome was strongly related to normally visualize basal cisterns in CT brain ( $p=0.002)$, normal/ borderline EEG activity $(p=0.03)$ and normal BAEP waves $(p=0.009)$. Disability was significantly related to slow activity waves $(p=0.015)$ and diffuse high voltage EEG discharges $(0.009)$. While mortality was significantly related to the presence of intracranial bleeding in CT brain $(p=0.02)$, silence EEG waves $(p=0.005)$ and absent BAEP waves $(0.012)$.

Conclusion: EEG and Auditory brainstem response are valuable as prognostic predictors of pediatric coma either due to medical or surgical causes. The Glasgow Coma Scale (GCS) has several important limitations as a predictor of survival in the general critically ill population while CT brain is mostly important for diagnostic rather than prognostic factor in comatosed children.
\end{abstract}

\section{Introduction}

Coma and other states of impaired consciousness represent a medical emergency in pediatric Intensive Care Unit (ICU). The potential causes are numerous, and the critical window for diagnosis and effective intervention is often short. The common causes of nontraumatic coma include central nervous system infections, metabolic encephalopathy (hepatic, uremic, diabetic ketoacidosis, etc...), intracranial hemorrhage, and stroke and status epilepticus [1].

The incidence of non-traumatic coma is about $30 / 100,000$ children per yr, and that of traumatic brain injury is about 670/100,000 [2].

The Glasgow Coma Scale (GCS) is a powerful predictor of survival and neurologic outcomes after head trauma, non-traumatic coma, ischemic stroke, subarachnoid hemorrhage, intracerebral hemorrhage, and meningitis. The GCS is also an independent predictor of survival in the general critically ill population and has been incorporated into a number of widely used prognostic intensive care scoring systems $[3,4]$.

Computed Tomography (CT) of the brain is warranted in virtually all patients with an acute onset of unexplained coma. CT will readily identify intracranial hemorrhage, hydrocephalus, brain edema, and compartmental shift and may suggest stroke, abscess, or tumor. CT brain has an unrevealing value in most instances of hypoxic ischemic or toxic-metabolic coma [5].

Neurophysiological methods [Electro-encephalogram (EEG) and Evoked Potentials (EPs)] provide functional assessment of the Central Nervous System (CNS). EEG is a dynamic physiologic process when it is important to evaluate events of time and space in neuronal network, so called time-space biodynamic of neuronal activity. The EEG reflects cortical neuronal activity modulated by both physiological and pathological diencephalic and brainstem influences and possibly affected by metabolic and/or toxic factors [6].

Evoked Potentials (EPs) remain a unique tool to demonstrate brainstem dysfunction interfering with Brainstem Auditory Evoked Potentials (BAEPs) and/or Somatosensory Evoked Potentials (SEPs). In some instances, BAEPs can demonstrate unexpected brainstem lesions in patients who were initially considered as post-anoxic, in which case heart failure or respiratory arrest are likely to be the consequence of primary brainstem damage rather than the primary cause of coma. Auditory Brainstem Response (ABR) represents the far field synchronous activity produced by neuronal fiber tracts of eighth

*Corresponding author: Sanaa M.Abdel Salam, Department of Pedatrics, Faculty of Medicine, Zagazig University, Egypt, E-mail: drsanaa74@yahoo.com

Received November 25, 2011; Accepted March 07, 2012; Published March 12 2012

Citation: El-Anwar MW, Ibrahim WM, Abdel Salam SM, Saleh SHA, Zeidan MA, et al. (2012) Glasgow Coma Scale, Brain Computerized Tomography and Neurophysiological Methods as Prognostic Factors of Pediatric Coma. J Neurol Neurophysiol 3:126. doi:10.4172/2155-9562.1000126

Copyright: (c) 2012 El-Anwar MW, et al. This is an open-access article distributed under the terms of the Creative Commons Attribution License, which permits unrestricted use, distribution, and reproduction in any medium, provided the original author and source are credited. 
cranial nerve and auditory brain stem pathway. The defect in BAEPs waves morphology and interpeak latency or interaural difference of wave latencies represents the most common disorders for neurootologic evaluation [7].

BAEP is used with expectation to evaluate disturbances of sensorineural pathways, identify the lesion of the brain tissue that is invisible in clinical evaluation or Computer Tomography (CT). The use of auditory evoked potentials (AEPs) offered greater precision than EEG parameters in evaluating neurological function because responses to stimulation of specific populations, or groups, of neurones could be identified. In contrast, EEG parameters, because of their simplified yet increasingly quantitative nature, permit electrical activity of the brain to be observed at any given moment [8].

The aim of the study was to compare the predictive values of clinical examinations combined with the recordings of Electroencephalography (EEG), Brainstem Auditory-Evoked Potentials (BAEP) and Computed Tomography (CT) of the brain in evaluation of coma outcome in children.

\section{Methods}

This was a prospective observational study conducted at ICU of Pediatric, Anaesthesia and Otorhinolaryngological departments, Zagazig University Hospitals on 20 comatosed patients including 11 males and 9 females with coma. They were subdivided into 2 groups: surgical and medical coma. Their mean age ranged between 3 to 14 years, treated and observed during the period between December 2009 to June 2011.

Coma was defined as state of unresponsiveness without evidence of awareness of self or environment from which the patient cannot be aroused by vocal or sensory stimuli. A score of 8 or less on Glasgow Coma Scale (pediatric adaptation) was mandatory [9].

Eight patients of surgical coma were included in this study: 4 with traumatic intracranial hemorrhage, 4 subarachnoid hemorrhage. While 12 children of medical causes of coma included : 1 patient with brain abscess, 1 brain tumour, 3 meningoencephalitis, 2 diabetic ketoacidosis (DKA), 2 uremia, 2 respiratory failure and 1 hypertensive encephalopathy.

All patients were subjected to:

- Full history taking.

- Thorough physical examination: including daily recording of the Glasgow Coma Scale (GCS)

- Routine laboratory investigations: including

1. Complete blood picture, ESR, liver function tests and thyroid function were assessed

2. Blood glucose, urea and serum creatinine.

3. Serum electrolytes and arterial blood gases (ABG).

- Routine coma care of children in ICU: both medical and surgical.

- Complete ear examination and tympanometric evaluation to exclude any external and/or middle ear pathology as it may affect results of Auditory Brainstem Response (ABR).

- CT brain was done on admission and on routine follow up.

In the present study, the first EEG was performed within the first
24 hours after admission as recommended by Synek [10]. EEG was recorded using an on-line 16-channel.

EEG system (Siemens-Elema system, Sweden). Sixteen scalp electrodes were applied according to international EEG 10-20 system. EEG data were collected using both referential linked ears; low frequency filter was set at $0.3 \mathrm{~Hz}$ and the high frequency filter at $30 \mathrm{~Hz}$.

Visual analysis of the raw EEG was performed by independent neurophysiologist and identified as different patterns of activity by dominant frequency, amplitude and stability.

BAEP testing was performed with recording electrodes placed as one active electrode placed on ipsilateral mastoid, one reference electrode placed at forehead, and ground electrode placed on the contralateral mastoid. The impedance level was to be kept below $5 \mathrm{Kohm}$; hearing threshold was detected for both ears separately. Mononeural activity stimuli consisting of refraction clicks of $0.1 \mathrm{msec}$. Square wave pulses were delivered through the ear phones at a rate of 1/ second. The intensity clicks were adjusted to be $90 \mathrm{dBnHL}$. Recording filters were $100-3000 \mathrm{~Hz}$ and 2000 stimuli were delivered.

The response picked up by recording electrodes BAEP, summated and averaged, and displayed on the screen. The results were graded as:

1. Normal response.

2. Unilateral or bilateral prolonged interpeak latencies between I and III, and III and V waves beyond 2 standard deviations of the mean value of control group.

3. Abnormal left-right ear differences beyond 2 standard deviations of the mean value of control group.

4. Absent waves [12].

The prognostic implications of single BAEPs were studied in two different sets of responses and recorded respectively during the first 48 hours of coma and at the beginning of the second week (day 6-7 of coma). These two sets of responses were respectively labeled "early" and "late" BAEPs; they were investigated separately to assess whether the moment at which recordings were made could influence their prognostic value.

BAEP modifications related to body temperature changes or observed under blood levels of anaesthetic drugs known to alter BAEPs were excluded $[13,14]$.

\section{CT brain}

CT scan of the brain was performed in radiology department (GE, high speed system), the patient was lying supine with the head in comfortable position, cuts were taken from the foramen magnum to the skull vault, thin cuts $(3 \mathrm{~mm})$ were taken in the posterior fossa , thicker cuts $(7 \mathrm{~mm})$ were taken at the higher levels. No contrast was taken in our study except in 2 cases where focal mass was noted and further examination with contrast administration was performed using iodinated contrast medium (after an intravenous bolus injection of 1 $\mathrm{mL}$ Urografin $/ \mathrm{kg}$ body weight). The data were collected and the images were analyzed.

\section{Statistical analysis}

Data were collected, entered and analysed by using SPSS, version 15. Data were expressed as number and percentage for qualitative variables, mean \pm standard deviation $(\mathrm{SD})$ for quantitative variables. Chi squared test $\left(\chi^{2}\right)$, student $t$-test and $\mathrm{F}$ test (ANNOVA) were used 
for comparison between studied groups. P value $<0.05$ was considered significant.

\section{Results}

Table 1 shows the demographic data of studied patients: there was younger age, lower Glasgow Coma Scale and more significant unfavourable outcome (death, disability) in patients with surgical coma (group 1) compared to patients with medical, (group 2).

Table 2 shows CT findings among studied subjects: there was a significant difference between both groups regarding the presence of brain edema and intracranial hemorrhage (100\% in group 1) while normally visualized basal cisterns were significantly more in group 2 $(\mathrm{p}=0.02)$

Table 3 shows EEG findings among studied subjects, Table 4 shows BAEP findings among studied subjects: there was no significant difference between both groups of patients regarding both EEG and BAEP findings.

Table 5 shows the relation of outcome of comatosed children to both BAEP, CT, EEG findings and GCS: Favourable outcome was significantly related to normally visualize basal cisterns in CT brain $(\mathrm{p}=0.002)$, normal borderline EEG activity $(\mathrm{p}=0.03)$ and normal BAEP waves $(p=0.009)$. Disability was significantly related to slow activity waves $(p=0.015)$ and diffuse high voltage EEG discharges $(p=0.009)$, moreover, 4 patients representing $100 \%$ of patients with disability had BAEP waves. While mortality was significantly related to the presence of intracranial bleeding in CT brain $(\mathrm{p}=0.02)$, silence EEG waves $(\mathrm{p}=0.005)$ and absent BAEP waves $(\mathrm{p}=0.012)$.

Figure 1 and 2 demonstrated ABR traces showing normal and prolonged I-III and I-V interpeak latencies. Figure 3 demonstrated ABR showing absent ABR waves.

\section{Discussion}

Coma is a medical emergency and may constitute a diagnostic and a therapeutic challenge for the intensivist. The Glasgow coma scale remains the "gold standard" for routine assessment of consciousness, but relies exclusively on behavioural responses. The degree of coma is commonly determined by the Glasgow scale, being that the score 3 in the scale corresponds to deep coma $[15,16,17]$.

In the present study, we noticed that younger age, lower Glasgow Coma Scale and more significant incidence of unfavourable outcome (death, disability) were present in patients with surgical coma than those of medical coma.

\begin{tabular}{|c|c|c|c|c|}
\hline & $\begin{array}{c}\text { Surgical } \\
(n=8)\end{array}$ & $\begin{array}{l}\text { Medical } \\
(n=12)\end{array}$ & $\begin{array}{c}\text { Test of } \\
\text { significance }\end{array}$ & p \\
\hline $\begin{array}{c}\text { Age (years) } \\
\text { Mean } \pm S D \\
\text { Range }\end{array}$ & $\begin{array}{c}6.8 \pm 3.2 \\
(3-14)\end{array}$ & $\begin{array}{c}9.3 \pm 1.9 \\
(6-12)\end{array}$ & $t=2.1$ & $0.04^{*}$ \\
\hline \multicolumn{5}{|l|}{ Sex } \\
\hline Male & $5(62.5 \%)$ & $6(50 \%)$ & \multirow{2}{*}{$X^{2}=0.01$} & \multirow{2}{*}{0.92} \\
\hline Female & $3(37.5 \%)$ & $6(50 \%)$ & & \\
\hline \multicolumn{5}{|l|}{ Outcome } \\
\hline Death & $6(75 \%)$ & $3(25 \%)$ & \multirow{3}{*}{$X^{2}=7.5$} & \multirow{3}{*}{$0.02^{*}$} \\
\hline Disable & $2(25 \%)$ & $2(16.7 \%)$ & & \\
\hline Good & $0(0 \%)$ & $7(58.3 \%)$ & & \\
\hline $\begin{array}{l}\text { Mean } \pm S D \\
\text { Range }\end{array}$ & $\begin{array}{c}4.3 \pm 0.5 \\
(4-5)\end{array}$ & $\begin{array}{c}5.3 \pm 0.98 \\
(4-7)\end{array}$ & $t=2.3$ & $0.03^{*}$ \\
\hline
\end{tabular}

$P<0.05$ significant, $<0.001$ highly significant,$>0.05$ non significant.

Table 1: Demographic data of studied patients.

\begin{tabular}{|l|c|c|c|c|c|c|}
\hline \multirow{2}{*}{\multicolumn{1}{|c|}{ Findings }} & \multicolumn{2}{c|}{$\begin{array}{c}\text { Surgical } \\
(\mathbf{n}=\mathbf{8})\end{array}$} & \multicolumn{2}{c|}{$\begin{array}{c}\text { Medical } \\
(\mathbf{n = 1 2})\end{array}$} & \multirow{2}{*}{$\mathbf{X}^{2}$} & \multirow{2}{*}{$\mathbf{p}$} \\
\cline { 2 - 7 } & No & $\%$ & No & $\%$ & & \\
\hline Intracranial bleeding & 8 & 100 & 0 & 0 & 16.05 & $<0.001^{\text {** }}$ \\
\hline Cerebral edema & 8 & 100 & 4 & 33.3 & 6.33 & $<0.001^{\text {** }}$ \\
\hline Hydrocephalus & 2 & 25 & 1 & 8.3 & 0.15 & 0.7 \\
\hline Focal mass & 0 & 0 & 2 & 16.7 & 0.21 & 0.6 \\
\hline $\begin{array}{l}\text { Normal visualization of basal } \\
\text { cisterns }\end{array}$ & 0 & 0 & 7 & 58.3 & 4.84 & $0.02^{*}$ \\
\hline
\end{tabular}

$P<0.05$ significant, $<0.001$ highly significant,$>0.05$ non significant.

Table 2: CT findings in studied patients.

\begin{tabular}{|l|c|c|c|c|c|c|}
\hline \multirow{2}{*}{\multicolumn{1}{|c|}{ Findings }} & \multicolumn{2}{|c|}{$\begin{array}{c}\text { Surgical } \\
\text { (n= 8) }\end{array}$} & \multicolumn{2}{c|}{$\begin{array}{c}\text { Medical } \\
(\mathbf{n = 1 2 )}\end{array}$} & \multirow{2}{*}{$\mathbf{X}^{2}$} & \multirow{2}{*}{$\mathbf{p}$} \\
\cline { 2 - 7 } & No & $\%$ & No & $\%$ & & \\
\hline Normal/borderline & 0 & 0 & 3 & 25 & 0.8 & 0.4 \\
\hline I-Slow activity & 2 & 25 & 3 & 25 & 0 & 1.0 \\
\hline II- Generalized low voltage & 2 & 25 & 5 & 41.7 & 0.08 & 0.8 \\
\hline III- Silence & 4 & 50 & 2 & 16.7 & 1.2 & 0.3 \\
\hline IV- Diffuse high voltage & 4 & 50 & 3 & 25 & 0.45 & 0.5 \\
\hline Discharges focal & 2 & 25 & 2 & 16.7 & 0.01 & 0.9 \\
\hline
\end{tabular}

$\mathrm{P}<0.05$ significant, $<0.001$ highly significant, $>0.05$ non significant

Table 3: EEG findings in studied patients.

\begin{tabular}{|l|c|c|c|c|c|c|}
\hline \multirow{2}{*}{\multicolumn{1}{|c|}{ Findings }} & \multicolumn{2}{|c|}{$\begin{array}{c}\text { Surgical } \\
\text { (n= 8) }\end{array}$} & \multicolumn{2}{c|}{$\begin{array}{c}\text { Medical } \\
(\mathbf{n = 1 2})\end{array}$} & \multirow{2}{*}{$\mathbf{X}^{2}$} & \multirow{2}{*}{$\mathbf{p}$} \\
\cline { 1 - 6 } & No & $\mathbf{\%}$ & No & $\%$ & & \\
\hline Normal bilateral BAEP & 0 & 0 & 4 & 33.3 & 1.58 & 0.2 \\
\hline Delayed BAEP & 6 & 75 & 5 & 41.7 & 1.02 & 0.3 \\
\hline Absent BAEP & 2 & 25 & 3 & 25 & 0.28 & 0.6 \\
\hline
\end{tabular}

Table 4: BAEP findings in studied patients.

The GCS has several important limitations. Subtle alterations in wakefulness and brainstem findings may not be captured by the GCS. A full GCS cannot be obtained in patients who are endotracheally intubated, are sedated, or have craniofacial trauma or in patients with dominant hemisphere lesions and aphasia. Mid range scores may result in different combinations of the three components yielding equivalent total scores that do not reflect the same degree of unconsciousness. Finally, differences in the higher GCS range correlate poorly with outcome and neuroimaging findings $[18,19]$.

Electroencephalogram (EEG) is useful in evaluation of patients with altered sensorium. Diffuse theta and delta activity, absence of faster frequencies, and intermittent rhythmic delta activity are characteristic of severe encephalopathies. Specific abnormalities may include epileptiform activity consistent with absence or complex partial status; triphasic waves indicating hepatic or uremic encephalopathy; and periodic lateralizing epileptiform discharges, suggesting herpes encephalitis [20].

Five grades of EEG abnormality in coma are internationally accepted: alpha rhythm, dominant theta, diffuse dominant delta, burst suppression and iso electric. At 48 hours, these grades provide prediction with an accuracy of about $88 \%$. The main advantage of the EEG is that it provides on-line assessment of the cerebral cortex, contrary to the EPs, which summarize the functional status of the tested CNS structures over the time needed for averaging [21].

Our results showed that there was no significant difference between patients of surgical and medical coma regarding EEG findings. Moreover, favourable outcome was significantly related to normal/ 
Page 4 of 6

\begin{tabular}{|c|c|c|c|c|c|c|c|c|}
\hline & \multicolumn{2}{|c|}{ Death $N=(9)$} & \multicolumn{2}{|c|}{ Disable $N=(4)$} & \multicolumn{2}{|c|}{ Good N=(7) } & \multirow{2}{*}{$\mathbf{x}^{2}$} & \multirow[b]{2}{*}{$\mathbf{p}$} \\
\hline & No & $\%$ & No & $\%$ & No & $\%$ & & \\
\hline \multicolumn{9}{|l|}{ BAEP findings } \\
\hline Normal bilateral & 0 & 0 & 0 & 0 & 4 & 57.1 & 9.29 & $0.009^{*}$ \\
\hline Delayed & 4 & 44.4 & 4 & 100 & 3 & 42.9 & 4.09 & 0.12 \\
\hline Absent & 5 & 55.6 & 0 & 0 & 0 & 0 & 8.15 & $0.012^{*}$ \\
\hline \multicolumn{9}{|l|}{ CT findings } \\
\hline Intracranial bleeding & 6 & 66.7 & 2 & 50 & 0 & 0 & 7.5 & $0.02^{*}$ \\
\hline Cerebral edema & 7 & 77.8 & 2 & 50 & 3 & 42.9 & 2.21 & 0.33 \\
\hline Hydrocephalus & 2 & 22.2 & 1 & 25 & 0 & 0 & 1.92 & 0.38 \\
\hline Focal mass & 0 & 0 & 1 & 25 & 1 & 14.3 & 2.14 & 0.34 \\
\hline Normal visualization of basal cisterns & 0 & 0 & 1 & 25 & 6 & 85.7 & 12.94 & $0.002^{*}$ \\
\hline \multicolumn{9}{|l|}{ EEG findings } \\
\hline I- Normal/borderline & 0 & 0 & 0 & 0 & 3 & 42.9 & 6.55 & $0.03^{*}$ \\
\hline II- Slow activity & 0 & 0 & 3 & 75 & 2 & 28.6 & 8.38 & $0.015^{*}$ \\
\hline III-Generalized low voltage & 4 & 44.4 & 0 & 0 & 3 & 42.9 & 2.7 & 0.25 \\
\hline IV-Silence & 6 & 66.7 & 0 & 0 & 0 & 0 & 10.48 & $0.005^{*}$ \\
\hline V-Diffuse high voltage & 2 & 22.2 & 4 & 100 & 1 & 14.3 & 9.39 & $0.009^{*}$ \\
\hline VI - Discharges focal & 2 & 22.2 & 1 & 25 & 1 & 14.3 & 0.23 & 0.88 \\
\hline \multicolumn{9}{|l|}{ GCS findings } \\
\hline Mean \pm SD & \multicolumn{2}{|c|}{$4.86 \pm 0.9$} & \multicolumn{2}{|c|}{$4.2 \pm 0.5$} & \multicolumn{2}{|c|}{$5.6 \pm 1$} & \multirow{2}{*}{3.09} & \multirow{2}{*}{0.07} \\
\hline Range & \multicolumn{2}{|c|}{$4-6$} & \multicolumn{2}{|c|}{$4-5$} & & & & \\
\hline
\end{tabular}

$P<0.05$ significant, $<0.001$ highly significant, $>0.05$ non significant.

Table 5: Relation between BAEP, CT, EEG and GCS findings and the outcome in studied patients.

borderline EEG activity ( $\mathrm{p}=0.03)$. While, disability was significantly related to slow activity waves $(\mathrm{p}=0.015)$ and diffuse high voltage EEG discharges (0.009). Mortality was significantly related to the presence of silence EEG waves ( $\mathrm{p}=0.005)$.

Tasker et al. [22] also found that all of the comatosed children with low amplitude EEG activity or electrocerebral silence had a poor neurological outcome. EEG patterns associated with poor outcome reported earlier by Johnston and Seshia [23] included burst suppression, alpha-like activity, very low amplitude activity and electrocerebral silence. A normal or borderline EEG with preservation of reactivity was associated with a significantly better neurological outcome as compared with abnormal EEG; more than $90 \%$ of survivors with abnormal EEG had neurological sequelae.

Tsalikian et al. [24] suggested a positive correlation between electroencephalographic abnormalities and the degree of metabolic control in diabetic children.

Our study showed that there was a significant difference between both groups regarding the presence of brain edema and intracranial hemorrhage in CT brain images (100\% in group 1) while normally visualized basal cisterns were significantly more in group $2(\mathrm{p}=0.02)$. Moreover, favourable outcome was significantly related to normally visualized basal cisterns in CT brain $(\mathrm{p}=0.002)$, while mortality was significantly related to the presence of intracranial bleeding in CT brain $(\mathrm{p}=0.02)$.

In a study performed by Singhi et al. [25], CT findings were useful predictor of outcome across various etiologic categories. Presence of intracerebral bleeding was associated with a poor outcome as two-third of these children died, and 2 of the 3 who survived had moderate or severe disability. On the other hand, the presence of hydrocephalus in CT Scan, which happened to be the commonest CT finding; indicated a better chance of survival. CT scan provided useful diagnostic information on patients with unsuspected intracranial bleed (who had no history of trauma) and in defining the cause of coma and raised intracranial pressure in a very large number of patients. In addition to providing useful information on the extent of injury, valuable prognostic information could also be obtained from the CT scan.

In patients with newly diagnosed type I diabetes mellitus, the first episode of DKA may not be recognized clinically. This results in a large accumulation of osmolytes which cause intracellular edema. On CT examination, cerebral edema is recognized as a loss of the gray-white matter interface, effacement of the sulci, and decrease in ventricular size [26].

Fatal cerebral oedema with herniation as a complication of diabetic keto-acidosis appears to be more common in childhood than in adults. More than half the recorded cases occurred in newly diagnosed diabetics during their first episode of ketoacidosis [27].

The present study showed that there was no significant difference between studied groups regarding BAEP findings.

Our results showed that favorable outcome was significantly related to normal BAEP waves $(\mathrm{p}=0.009)$ while mortality was significantly related to absent BAEP waves ( $\mathrm{p}=0.012)$. Moreover, 4 patients $(100 \%)$ with disabilities had delayed BAEP findings and these disabilities were observed later after discharge in the form of neurological deficits or recurrence of coma.

The value of evoked potentials for assessment of functional impairment of afferent pathways has been documented in a large number of studies in patients suffering from non-traumatic cerebral disease. Two main advantages of EPs, when compared to the EEG, are their relative insensitivity to the environmental noise (owing to the averaging process) and, before all, the fact that they provide straightforward brainstem assessment [28].

The interpeak latency of BAEPs has been reported as being almost constantly normal when recorded during the first six hours of traumatic coma. This suggests that most abnormalities encountered later are secondary to hemisphere lesions, and reflect an ongoing process of rostrocaudal deterioration of the brainstem. Discrete brainstem lesions 


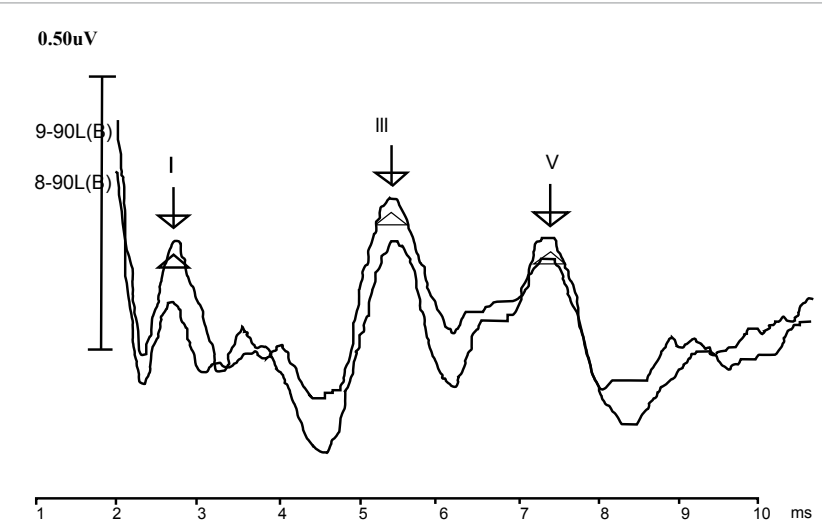

$\mathrm{P}<0.05$

Figure 1: ABR trace showing normal I-III and I-V interpeak latencies.

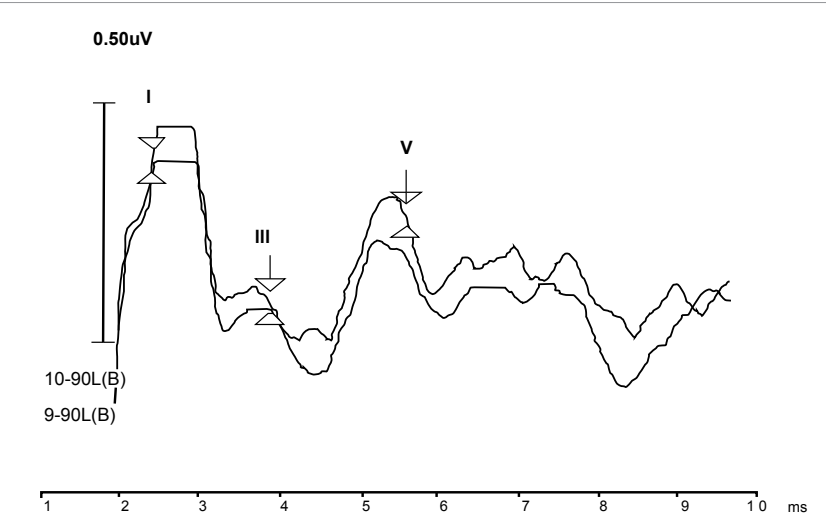

Figure 2: ABR trace showing prolonged I-III and I-V interpeak latencies.

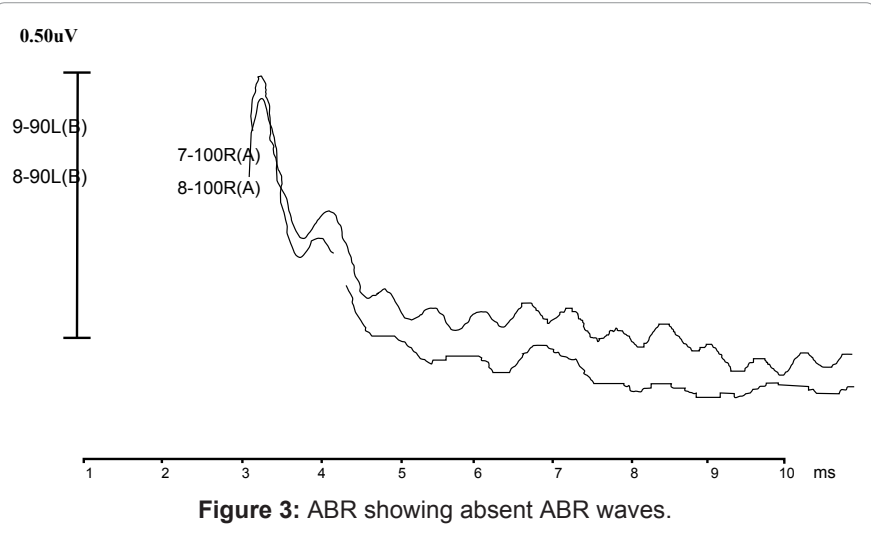

may, however, also induce severe BAEP abnormalities (like complete absence of waves) if they involve the central auditory pathways [29,30].

Balogh et al. [31] proved that BAEPs testing provides relevant prognostic information, since improvement of graded BAEPs. Moreover, Chiappa [32] said that BAEP provided a sufficient safety margin to be used in comatosed patients and remain an indicator of a preserved brain-stem function in difficult clinical situations. Unlike the cortical auditory brain potentials (late evoked potentials) in patients with severe cerebral lesions, BAEPs have much greater information value. Their waveforms are more stable and they are less influenced by various exogenous and endogenous factors
Haupt et al. [33] assumed that the reason for the abnormal BAEP in patients with subarachnoid hemorrhage $(\mathrm{SAH})$ was the increased intracranial pressure as a result of SAH. Moreover, Wada et al. [34] believed that brainstem secondary ischemia, resulting from increased intracranial pressure, affects the III/V interpeak latency.

In published series, the average incidence of unfavourable evolution (severe disabilities or death) was about $30 \%$, but ranges from 0 to more than $50 \%$ in patients with bilaterally normal BAEP during the acute phase of traumatic coma [35].

A study performed by Larrea et al. [36] showed that $46 \%$ of patients with normal "early" BAEPs did unfavourably, a figure comparable to other series dealing with patients having low Glasgow Coma Scores [37].

Some studies have suggested that a favourable vital outcome might be predicted by normal BAEP recorded beyond the first days of coma. The reason for this is probably that death after traumatic or vascular coma mainly occurs during the first week, and especially during the first 48 hours after the accident $[38,39]$.

Jardim et al. [40] found that the BAEP presented significant relationship ( $\mathrm{p}=0.015)$ with the clinical outcome. It demonstrated high specificity (100\%) in the prediction of death in patients in Glasgow coma and, therefore, it makes possible to assist the diagnosis of brain death.

\section{Conclusion}

EEG and auditory evoked potential measurements should be involved into systematic routine use in the pediatric ICU for comatosed children either due to medical or surgical causes. This would enable earlier detection of cerebral distress and allow critical intervention.

Glasgow coma scale results alone may have limited prognostic value in absence of other objective neurophysiologic investigation data concerning the coma outcome in children.

Coma prognosis may be worse if pathological poor brainstem auditory-evoked potentials correlate with pathological dynamic changes in electroencephalography and brain lesions diagnosed during computerized tomography.

\section{References}

1. Sharma S, Kochar GS, Sankhyan N, Gulati S (2010) Approach to the child with coma. Indian J Pediatr 77: 1279-1287.

2. McCarthy ML, Serpi T, Kufera JA, Demeter LA, Paidas C (2002) Factors influencing admission among children with traumatic brain injury. Acad Emerg Med 9: 684-693.

3. Booth CM, Boone RH, Tomlinson G, Detsky AS (2004) Is this patient dead, vegetative, or severely neurologically impaired? Assessing outcome for comatose survivors of cardiac arrest. JAMA 291: 870-879.

4. Marshall JC, Cook DJ, Christou NV, Bernard GR, Sprung AL, et al. (1995) Multiple organ dysfunction score: A reliable descriptor of a complex clinical outcome. Crit Care Med 23: 1638-1652.

5. Rafanan AL, Kakulavar P, Perl J 2nd, Andrefsky JC, Nelson DR, et al. (2000) Head computed tomography in medical intensive care unit patients: clinical indications. Crit Care Med 28: 1306-1309.

6. Guérit JM, Fischer C, Facco E, Tinuper P, Murri L, et al. (1999) Standards of clinical practice of EEG and EPs in comatose and other unresponsive states. In: Recommendations for the Practice of Clinical Neurophysiology: Guidelines of the International Federation of Clinical Neurophysiology. Amsterdam: Elsevier 52: 117-131.

7. Kane NM, Butler SR, Simpson T (2000) Coma outcome prediction using eventrelated potentials: P-3 and mismatch negativity. Audiol Neurootol 5: 186-191. 
Citation: El-Anwar MW, Ibrahim WM, Abdel Salam SM, Saleh SH.A, Zeidan MA, et al. (2012) Glasgow Coma Scale, Brain Computerized Tomography and Neurophysiological Methods as Prognostic Factors of Pediatric Coma. J Neurol Neurophysiol 3:126. doi:10.4172/2155-9562.1000126

8. John ER, Prichep LS, Kox W, Valdés-Sosa P, Bosch-Bayard J, et al. (2001) Invariant reversible QEEG effects of anesthetics. Conscious Cogn 10: 165-183.

9. Bansal A, Singhi SC, Singhi PD, Khandelwal N, Ramesh S (2005) Nontraumatic coma. Ind J Pediatr 72: 467-473.

10. Synek VM (1990) Value of revised EEG coma scale for prognosis after cerebral anoxia and diffuse head injury. Clin Electroencephalogr 21: 25-30.

11. Guérit JM (1999) Medical technology assessment EEG and evoked potentials in the intensive care unit. Neurophysiol Clin 29: 301-317.

12. Shin JOH (1993) Somatosensory evoked potentials in peripheral neuropathy. In: Clinical Electromyography. Lippincott Williams and Wilkins, Baltimore, Maryland, USA.

13. Mauguiere F, Garcia-Larrea L, Bertrand O (1992) Utility and uncertainties of evoked potential monitoring in the ICU. Evoked Potentials 153-167.

14. Javel E, Mouney DF, McGee JA, Walsh EJ (1982) Auditory brainstem responses during systemic infusion of lidocaine. Arch Otolaryng 108: 71-76.

15. Schnakers C, Vanhaudenhuyse A, Giacino J, Ventura M, Boly M, et al. (2009) Diagnostic accuracy of the vegetative and minimally conscious state: Clinical consensus versus standardized neurobehavioral assessment. BMC Neurology 9: 35.

16. Giacino JT, Smart CM (2007) Recent advances in behavioral assessment of individuals with disorders of consciousness. Curr Opin Neurol 20: 614-619.

17. Teasdale G, Jennett B (1974) Assessment of coma and impaired consciousness. A pratical scale. Lancet 2: 81-84.

18. Giacino J, Whyte J (2005) The vegetative and minimally conscious States: current knowledgeand remaining questions. J Head Trauma Rehabil 20: 30-50.

19. Sternbach GL (2000) The Glasgow coma scale. J Emerg Med 19: 67-71.

20. Misra UK, Kalita J (1988) A comparative study of Japanese and herpes simplex encephalitides. Electromyogr Clin Neurophysiol 38: 41-46.

21. Edgren E, Hedstrend U, Nordin M, Rydin E, Ronquist G (1987) Prediction of outcome after cardiac arrest. Crit Care Med 15: 820-825

22. Tasker RC, Boyd S, Harden A, Matthew DJ (1988) Monitoring in non-traumatic coma. Part II: electroencephalography. Arch Dis Child 63: 895-899.

23. Johnston B, Seshia SS (1984) Prediction of outcome in non-traumatic coma in childhood. Acta Neurol Scand 69: 417-427.

24. Tsalikian E, Becker DJ, Crumrine PK, Daneman D, Drash AL (1981) Electroencephalographic changes in diabetic ketosis in children with newly and previously diagnosed insulin-dependent diabetes mellitus. J Pediatr 98: 355359

25. Singhi PD, Bansal A, Ramesh S, Khandelwal N, Singhi SC (2005) Predictive value of electroencephalography and computed tomography in childhood nontraumatic coma. Indian J Pediatr 72: 475-479.

26. Hoffman WH, Steinhart KM, El-Gammal T, Steele S, Cuadrado AR, et al. (1988) Cranial CT in children and adolescents with diabetic ketoacidosis. AJNR Am J Neuroradiol 9: 733-739.

27. Rosenbloom AL, Riley WJ, Weber IT, Malone JI, Donnelly WH (1980) Cerebra edema complicating diabetic ketoacidosis in childhood. J Pediatr 96: 357-361.

28. Haupt WF, Birkmann C, Halber M (2000) Serial evoked potentials and outcome in cerebrovascular critical care patients. J Clin Neurophysiol 17: 326-330.

29. Cenzato M, Ducati A, Fava E, Rampini P, Giovanelli M, et al. (1988) Evaluation of traumatic coma by means of multimodality evoked potentials. Evoked potentials: ICU and surgical monitoring. Berlin: Springer-Verlag 153-167.

30. Ferbert A, Buchner H, Bruckmann H, Zeumer H, Hacke W (1988) Evoked potentials in basilar artery thrombosis: Correlation with clinical and angiographic findings. Electroencephalogr Clin Neurophysiol 69: 136-147.

31. Balogh A, Wedekind C, Klug N (2001) Does wave $V$ of BAEP pertain to the prognosis of coma? Neurophysiol Clin 31: 406-411.

32. Chiappa KH (1990) Methodology. Evoked potentials in clinical medicine. (2ndedn), New York

33. Haupt WF, Hojer C, Pawlik G (2005) Prognostic value of evoked potentials and clinical grading in primary SAH. Acta Neurochir 137: 146-150.

34. Wada SI, Matsuoka S, Urazaki El, Yadomi C (1988) Quantitative analysis of reversible dysfunction of brain-stem midline structures caused by disturbance of basilar artery blood flow with the auditory brainstem responses. Electroenceph Clin Neurophysiol 69: 148-159.

35. Garcia-Larrea L (1992) Evoked potentials in the comatose patient. Manual of Clinical Neurophysiology, London.

36. Larrea LG, Artru F, Bertrand O, Pernier J, Mauguière F (1992) The combined monitoring of brainstem auditory evoked potentials and intracranial pressure in coma: A study of 57 patients. J Neurol Neurosurg Psychiatry 55: 792-798.

37. Kaga K, Nagai T, Takamor A, Marsh RR (1985) Auditory short-middle- and long-latency responses in acutely comatose patients. Laryngoscope 95: 321325.

38. De Weerd AW, Groeneveld C (1985) The use of evoked potentials in the management of patients with severe cerebral trauma. Acta Neurol Scand 72 489-494.

39. Plum F, Posner J (1980) Diagnosis of stupor and coma. (3rdedn), Philadelphia

40. Jardim M, Person OC, Rapoport PR (2008) [Brainstem auditory evoked potentials as a method to assist the diagnosis of brain death]. Pro Fono 20 123-128. 